Artigos

\title{
0 trabalho de teleatendimento no Brasil: um estado da arte ${ }^{\mathrm{T}}$
}

Márcia de Paula Leite 2

Liliane Bordignon ${ }^{3}$

Resumo: $\mathrm{O}$ artigo apresenta uma análise do trabalho no setor de telemarketing no Brasil, realizada com base na produção do conhecimento sobre o tema. $\mathrm{O}$ objetivo é fundamentar o debate sobre as características do setor, com especial destaque para a questão da sua organização internacional, bem como da relocalização das empresas no território nacional. Com base nessa configuração do setor, será analisado o tipo de trabalho nele desenvolvido, buscando mostrar também as formas de organização e resistência dos trabalhadores e trabalhadoras inseridos(as) no teleatendimento.

Palavras-chave: teleatendimento, terceirização, relocalização

\section{Call-center work in Brazil: a state of the art}

Abstract: The paper presents an analysis of the work in the telemarketing sector in Brazil, based on the production of knowledge about the subject. The objective is to support the debate on the characteristics of the sector, with special emphasis on

1 Trabalho realizado no âmbito do Projeto Temático FAPESP (2013-2018) - Contradições do trabalho no Brasil atual: formalização, precariedade, terceirização e regulação, coordenado por Márcia de Paula Leite.

2 Faculdade de Educação da Universidade Estadual de Campinas (FE/Unicamp) - Campinas - Brasil mpleite48@gmail.com

3 Doutoranda do Programa de Pós-graduação em Educação da Universidade Estadual de Campinas (FE/ Unicamp) - Campinas - Brasil - lilianebordignon@yahoo.com.br 
the question of its international organization, as well as the relocation of companies in the national territory. Based on this configuration of the sector, the type of work developed in it will be analyzed, seeking also to demonstrate the forms of organization and resistance of the workers included in the telemarketing.

\section{Keywords: telemarketing, outsourcing, relocation}

\section{Introdução}

Acompanhando o debate internacional, a sociologia do trabalho brasileira tem se debruçado ultimamente sobre o estudo do trabalho em call centers. Nesse sentido, este texto se propõe a retomar a discussão sobre o tema com base nos estudos já realizados no Brasil ${ }^{4}$, inserindo a análise do setor e do trabalho que nele se desenvolve na discussão sobre os processos de globalização e terceirização ou do que Miriam Glucksmann (2009) tem chamado de processos globais de provisão e consumo.

Considerando que o trabalho realizado nos call centers só podem ser entendidos como parte de um amplo processo produtivo, que implica a produção, distribuição, venda e consumo, a autora propõe que se pense esse trabalho com base nas relações que as empresas desenvolvem com a produção e distribuição, por um lado, e com a venda e o consumo, por outro. Isso tem permitido compreender os processos de terceirização e deslocamento que marcam a formação do setor e que continuam se desencadeando, assim como a dinâmica de organização das empresas e os tipos de atividade que nelas se desenvolvem. De acordo com a autora, isso significa considerar a divisão do trabalho que ocorre no setor não só em termos de gênero e etnicidade, mas também de acordo com sua distribuição entre diferentes países e localidades (Glucksmann, 2009: 883).

4 Evidentemente, os textos discutidos não contemplam o conjunto dos estudos já realizados sobre o setor, o que seria impossível em um trabalho desta dimensão. Dessa forma, selecionamos aqui apenas aqueles mais conhecidos e divulgados sobre o tema.

Para além dos estudos selecionados e citados na elaboração deste artigo, encontramos, com base em levantamento bibliográfico pela busca com a palavra-chave telemarketing: 44 artigos no banco de dados do Scielo (Disponível em: <https://search.scielo.org/>. Acesso em: 10 set. 2019), a maioria publicada em 2006; 84 dissertações de mestrado e 20 teses de doutorado no banco de teses e dissertações da Capes (Disponível em: <http://catalogodeteses.capes.gov.br/catalogo-teses/>. Acesso em: 10 set. 2019); destacamos que em 2017 foram publicados 27 trabalhos. Na Biblioteca Digital Brasileira de Teses e Dissertações (BDBT - Disponível em: <http://bdtd.ibict.br>. Acesso em: 10 set. 2019), que está associada ao banco da Capes, encontramos 85 trabalhos, sendo 66 dissertações de mestrado e 19 teses de doutorado. Dentre as teses encontradas estão aquelas que foram selecionadas como referências neste artigo, como Tais Viudes (2010), Mônica Cavaignac (2010), Cláudia Nogueira (2006) e Selma Venco (2003). 
Vale lembrar que, embora haja já uma vasta bibliografia sobre os call centers e seus trabalhadores(as) no Brasil, poucos são os estudos que analisam o trabalho no setor com base nessa perspectiva ${ }^{5}$.

Baseia-se do pressuposto de que o teleatendimento consiste em um tipo de trabalho do setor de serviços relativamente novo no que concerne à sua configuração, tendo em vista que quase não existia até quatro décadas atrás ou, quando existia, era realizado no interior de grandes empresas comerciais, industriais ou financeiras. Seu surgimento enquanto um setor específico da atividade econômica se dá com a difusão do processo de terceirização que toma conta da economia internacional a partir dos anos 1970, quando as empresas começam a externalizar suas atividades de contato com os clientes e de marketing, e se difunde rapidamente a partir de então, acompanhando a evolução das tecnologias de informação e comunicação.

Conforme explicita Jordy Micheli (2012: 151), no início, as empresas iniciaram sua incursão nos distintos mercados com centros de chamada integrados à sua própria estrutura, adaptando-os como centros operativos novos; outras os transformaram em empresas voltadas a oferecer o serviço para empresas diferentes; e um terceiro grupo surgiu como outsourcing desde o início. Segundo o autor,

na atualidade, é este terceiro grupo que marca o dinamismo internacional da indústria ${ }^{6}$, conformando um setor multinacional que promove investimentos, emprego e estândares em diversos países. A terceirização aparece fortemente relacionada com o dinamismo do mercado e sua segmentação/ proteção, posto que se trata de mercados internacionais em grande medida e as empresas da indústria de call center os podem abarcar mediante políticas de relocalização (Micheli, 2012: 151).

A terceirização é, portanto, constitutiva do setor, assim como os processos de relocalização das empresas, na busca de vantagens comparativas7. Estes ocorrem tanto pelas políticas de offshoring, que as grandes empresas internacionais do setor têm implementado na tentativa de encontrar trabalho mais barato

5 Destaque-se, nesse sentido, alguns estudos mais recentes que têm se detido sobre os processos de deslocamento das empresas no interior do país, como os de Braga (2012); Almeida (2013 e 2014) e Moraes (2017).

6 O autor considera que o setor configura uma indústria em função de sua "expansão como empresas de outsourcing que se transladam como multinacionais a qualquer parte do mundo, gerando emprego e transformando cadeias de valor" (Micheli, 2012: 148).

7 O conceito de vantagens comparativas vem da economia clássica e designa a possibilidade de que um país ou região seja capaz de produzir alguma mercadoria ou serviço a um menor custo absoluto em relação aos/às demais. 
em outros países ${ }^{8}$, como na relocalização das empresas no interior dos países, como vem ocorrendo atualmente com o deslocamento de empresas multinacionais no Brasil para cidades do interior de São Paulo e para o Nordeste. Embora o offshoring não ocorra no caso do Brasil, tendo em vista que as multinacionais de call center aqui instaladas operam apenas no mercado interno, essa prática foi bastante comum na Argentina entre 2002 e 2008 (Del Bono; Leite, 2016), assim como é bastante frequente no México e em alguns países da América Central (Micheli, 2014).

A pesquisa de Renata Dutra (2017: 99-101) ressalta que, no caso de Salvador, capital que recebeu diferentes empresas de teleatendimento oriundas da região Sudeste, a atual gestão (2013-2010) ${ }^{9}$ da prefeitura da cidade concedeu isenção fiscal com objetivo de facilitar a instalação da empresa Atento, que prometia a criação imediata de 3.000 postos de trabalho. Isto significou a redução de $3 \%$ do Imposto Sobre Serviços (ISS) e 50\% do Imposto Predial e Territorial Urbano (IPTU) durante 4 anos. A autora aponta ainda que o número de teleatendentes na região, segundo os dados da RAIS, variou entre 1.795 operadores e 18.605 entre os anos de 2003-2015, representando um crescimento significativo do setor na região. A relocalização no interior do país vem sendo bastante intensa, especialmente a partir de 2010, provocando uma nova onda de migração de empresas para o Nordeste (Braga, 2012; Almeida, 2013; 2014; Moraes, 2017; Dutra, 2017), tal como ocorreu nos anos 1990, em que fábricas de calçado e confecção migraram para a região em busca de mão de obra barata, trabalhadores sem organização sindical e incentivos locais (Lima, 1997: 141-142).

A expansão do setor de telemarketing no país se insere, dessa forma, no processo de reestruturação das empresas que marcou a crise do fordismo e no intenso processo de terceirização que caracterizou a nova forma de organização empresarial. Ela se insere também no processo de globalização da economia e de formação de cadeias globais de valor ${ }^{10}$, por meio dos quais, buscando baratear seus custos de produção, as empresas detentoras de grandes marcas do setor industrial e de serviços foram concentrando o trabalho de planejamento, concepção e administração dos fornecedores. Ao mesmo tempo, elas

8 Acompanhando o processo de globalização e terceirização da economia, os processos de offshoring no setor de call center consistem na exportação de serviços voltados para um determinado mercado, os quais passam a ser feitos por subsidiárias situadas em outros países.

9 Gestão do prefeito Antônio Carlos Magalhães Neto (2013-2020).

10 Cadeias globais de valor consistem em aglomerações de empresas situadas em diferentes países do mundo, envolvidas na produção e distribuição de um mesmo produto. Para mais detalhes, ver Gereffi e Korzeniewicz (1993). Para mais detalhes sobre cadeias globais de valor no setor de call center ver Del Bono e Leite (2016). 
terceirizaram seus processos de produção e de oferta de serviços menos complexos para empresas situadas em outros países do mundo, especialmente aqueles em que o custo do trabalho é mais baixo, como o Brasil.

A expansão se insere, igualmente, no processo de privatização das empresas de telecomunicações, que começou a ocorrer sobretudo a partir dos anos 1980, quando o neoliberalismo se fortaleceu em nível mundial. Trata-se, portanto, de um setor que nasce sob a égide dos processos de terceirização e de privatização das telecomunicações e cuja expansão, bem como as características do trabalho nele desenvolvido não podem ser compreendidas fora desse contexto. Vale destacar que a tendência à terceirização não é responsável apenas pelo surgimento do setor, mas também pela terceirização de muitas atividades das empresas de telemarketing, assim como de trabalhadores que são contratados por empresas de subcontratação de força de trabalho para prestar serviços em empresas de telemarketing, em um processo de terceirização em cascata.

É essa conformação global do setor e o processo de terceirização que o marca desde seu surgimento que nos permite afirmar, por exemplo, que as atividades nele desenvolvidas são pouco complexas. Como explicita Miriam Glucksmann (2009: 880), "apesar de frequentemente subsumida ao processo de trabalho, a divisão do trabalho possui uma acepção mais ampla e sua análise tem o potencial para aperfeiçoar a compreensão de uma nova dinâmica de interdependência em novas escalas espaciais".

Nesse sentido, valeria ressaltar que as atividades desenvolvidas pelas empresas de call center que operam no país se concentram em provimento de informações (atenção ao cliente), bem como na venda de produtos. Em ambos os casos, as atividades seguem um modelo de interação bastante simples, "no qual a chamada é o último ponto da operação; as outras operações da cadeia de provisão de informações ocorrem previamente" (Del Bono; Leite, 2016: 31).

Por outro lado, a conformação do setor no país, com a migração de empresas para cidades menores do interior dos estados do Sudeste ou para cidades do Nordeste, significa uma divisão espacial entre o trabalho mais complexo, concentrado nas maiores e economicamente mais importantes cidades do país, e o trabalho mais simples, que imigra para o interior dos estados e para a região Nordeste. Conforme assinala Marina Almeida (2014: 2358), "a integração remota entre as unidades das empresas tem redefinido a hierarquia entre os lugares e áreas desvalorizadas têm sido (re)incorporadas à produção".

Inserindo a discussão sobre o trabalho no setor de telemarketing nesse processo mais global de produção e terceirização dos serviços, este texto debruça-se sobre esse setor no Brasil com base em uma análise da produção 
do conhecimento já desenvolvida sobre o tema. Por meio dele, pretendemos debater as características do setor, bem como do trabalho nele desenvolvido, buscando elucidar também as formas de organização dos trabalhadores e trabalhadoras nele inseridos(as).

\section{0 teleatendimento no Brasil}

As empresas de telemarketing são as principais desenvolvedoras do teleatendimento, prestando serviços de atendimento a clientes de outras empresas, como as de telecomunicações, grandes lojas, empresas de logística, bancos etc. É um dos ramos do setor de serviços que mais emprega no Brasil. As pesquisas de Hermes Costa e Elizardo Costa (2018), Ruy Braga (2012), Jessé Souza (2012), Ruy Braga e Ricardo Antunes (2009), Cláudia Nogueira (2006), e Selma Venco (2003) demonstram que os trabalhadores do setor são jovens, a maioria mulher, escolarizados, recebem em média 1,5 salários mínimos ${ }^{11}$ e possuem uma organização sindical frágil.

O trabalho no teleatendimento pode ser definido como "atividade remota realizada por meio de tecnologias da informação e comunicação (TICs), permitindo a obtenção de resultados num lugar diferente daquele ocupado pela pessoa que o realiza" (Rosenfield; Alves, 2011). O Ministério do Trabalho (MTE), por sua vez, na Norma Regulamentadora $\mathrm{n}^{\circ} 17(\mathrm{NR}-17)$, apresenta a seguinte definição de trabalho de teleatendimento/ telemarketing:

Entende-se como trabalho de teleatendimento/telemarketing aquele cuja comunicação com interlocutores clientes e usuários é realizada à distância (sic) por intermédio da voz e/ou mensagens eletrônicas, com a utilização simultânea de equipamentos de audição/escuta e fala telefônica e sistemas informatizados ou manuais de processamento de dados.

$\mathrm{Na}$ análise que ora apresentamos, consideraremos estas duas definições quando nos referirmos ao teletrabalho, teleatendimento ou trabalho no telemarketing. Ponderamos que se trata de um emprego que envolve necessariamente tecnologias de comunicação, como computadores, internet, rede telefônica etc., assim como passa necessariamente pela escuta e pela fala dos trabalhadores empregados. Tecnologia e força de trabalho agem juntas para a execução do serviço.

Observamos que muitas empresas terceirizam o serviço de apoio ao cliente $(\mathrm{SAC})$ e a venda de produtos por telefone, que são entregues para outras

11 Esse salário parece, contudo, ter baixado nos últimos tempos. Voltaremos ao assunto mais adiante. 
empresas especializadas no teleatendimento, como forma de otimizar e baratear a relação com o cliente. Nesse sentido, o teleatendimento é dividido em ativo e receptivo, como forma de otimizar a organização do trabalho. $\mathrm{O}$ receptivo "caracteriza-se pela recepção das ligações que não foram solucionadas no atendimento eletrônico e pelo encaminhamento de soluções aos clientes (Venco, 2003: 45). Já o telemarketing ativo caracteriza-se pela venda de produtos e serviços oferecidos pelas empresas, na qual o trabalhador age como promotor direto da venda por meio do telefone. Segundo Selma Venco (2003), o telemarketing ativo é um dos ramos mais facilmente terceirizados pelas grandes empresas, principalmente por não possuir uma vinculação mais direta com os problemas decorrentes de produtos e serviços por elas oferecidos.

Os estudos consultados indicam que foi em especial a partir da década de 1980 que as empresas de crédito, editoras, operadoras de telefonia etc., passaram a utilizar o telemarketing no Brasil como meio de vendas e atendimento aos clientes (Nogueira, 2006). Transferindo esses serviços que antes desenvolviam em seu interior ou simplesmente inaugurando-os com a oferta das empresas terceirizadas de telemarketing, as empresas começaram a se utilizar da prestação de serviços de vendas e apoio ao consumidor por empresas especializadas no serviço de teleatendimento, que iniciavam a operação no país, especialmente a partir de 1990, com a chegada das grandes multinacionais do setor. Renata Dutra (2016) adverte para o fato de que a prevalência da terceirização no setor consistiu em uma infração legislativa, devido à proibição da terceirização em atividades fim das empresas até o início de $2017^{12}$. Segundo a autora, de acordo com os dados do DIEESE para 2014,

Neste setor, no qual prevalecem contratações terceirizadas, vem-se observando, desde a década de 1990, a prática desenfreada de terceirização de atividades fim, seja por instituições bancárias (responsáveis por 31\% das contratações de empresas de teleatendimento), seja por empresas do setor de telecomunicações (responsáveis por 50\% das contratações de empresas de teleatendimento (Dutra, 2016: 72).

Na década de 1990, o desenvolvimento de uma política econômica baseada na ampla abertura da economia nacional para a entrada de empresas e capital internacional, quando da adoção de pressupostos políticos e econômicos neoliberais, produziu um ciclo de privatizações de empresas estatais. Nesse processo,

12 A legislação em vigor até março de 2017 só permitia a terceirização em atividades meio das empresas (Súmula 331 do Tribunal Superior do Trabalho). 
a telecomunicação passou de serviço público, organizado exclusivamente pelo Estado, para um serviço privado ofertado de acordo com as condições de compra dos indivíduos e corporações.

Além das consequências da abertura econômica, as empresas de telecomunicações brasileiras, como a Telebrás ${ }^{13}$, suportavam pressões decorrentes do processo de reestruturação produtiva de empresas estadunidenses, europeias e japonesas, que estavam operando amplas transformações tecnológicas e de gestão do trabalho em suas cadeias de produção. Comparativamente, as empresas estatais brasileiras estavam pouco desenvolvidas devido à falta de investimentos públicos, o que as tornava incapazes de produzir e ofertar os serviços demandados pela população. Este fato também contribuiu para sustentar ideologicamente o projeto de privatização das empresas estatais (Cavalcante, 2009).

Após essa nova base proporcionada pelas empresas de telecomunicações que ampliaram o atendimento da telefonia fixa e móvel -, as empresas de teleatendimento ampliaram seus serviços. Elas assumiram, inclusive, setores terceirizados de atendimento receptivos e ativos dos novos grupos privados de telecomunicações, como demonstra Sávio Cavalcante (2014). Um total de 76\% das empresas de teleatendimento foram criadas após 1998, ano de conclusão da privatização do sistema Telebrás.

Como adverte Marina Almeida, "após as privatizações, as novas controladoras do sistema telefônico brasileiro criaram empresas especializadas nos serviços de teleatendimento (Contact Center) ${ }^{14}$ com o objetivo de reduzir seus custos de produção. A criação dos Contact Centers, ao mesmo tempo em que desobrigou as teles das despesas com a mão de obra, impulsionou também o surgimento de novos serviços: atendimento ao consumidor, suporte técnico, televendas, cobrança e recuperação de crédito" (Almeida, 2014: 2358).

A reestruturação das empresas de telecomunicações no Brasil promoveu a transformação do setor, alterou as bases tecnológicas da telefonia, duplicou o atendimento da telefonia fixa, o crescimento da telefonia celular e, em especial, proporcionou um enorme lucro para as empresas privatizadas (Cavalcante, 2009: 163-166). Com a ampliação da rede de telefonia, o teletrabalho se ampliou e foram organizadas empresas cada vez mais especializadas no teleatendimento, a maior parte delas sustentada por capital internacional, as quais passaram a

13 O Sistema Telebrás foi privatizado em 1998; após um processo de quebra do monopólio da empresa e um amplo investimento do Estado, as empresas foram concedidas a grupos privados nacionais e internacionais, que receberam as estruturas físicas, trabalhadores, seus recursos e estoques. Ver Sávio Cavalcante (2009). 
prestar serviços para outras empresas de diferentes setores da economia. Durante o governo Fernando Henrique Cardoso (1995-2002), este setor cresceu a uma taxa de $15 \%$ ao ano e no governo Lula da Silva (2003-2010) registrou uma taxa anual de 20\% (Braga, 2012: 187-188). Segundo Cláudia Nogueira (2006: 36), "nos 3 anos iniciais da década de 2000, o setor alcançou 235\% de crescimento; mesmo em um período de forte recessão na criação de postos de trabalho e com profundo índice de desemprego (...) esse segmento torna-se um dos maiores empregadores do país".

Este crescimento exponencial favoreceu um amplo processo de terceirização de serviços e vendas realizados por meio da telefonia. $\mathrm{O}$ caso da terceirização do teleatendimento nos bancos e nas próprias empresas de telecomunicações é emblemático (Venco, 2003; Filgueiras; Cavalcante, 2015). Analisando o processo de terceirização no teleatendimento ocorrido nas empresas de telecomunicações, no Brasil, Sávio Cavalcante (2014) ressalta que:

As operadoras de telecomunicações empregam diretamente um núcleo cada vez mais reduzido, principalmente em áreas técnicas de desenvolvimento de produtos e gestão central. $\mathrm{O}$ grosso dos trabalhadores está espalhado por centenas de empresas, de instaladores ${ }^{15}$ a operadores de call center, e há subcontratação até mesmo em áreas de projetos e sistemas de informação - daí o trabalho terceirizado ter graus distintos de especialização técnica. Da terceirização surgem formas mais diferenciadas, como as empresas "quarteirizadas", que intermediam as relações de subcontratação ou prestam serviços às terceirizadas (p. 211).

Em um primeiro momento, o crescimento do setor ocorreu de forma concentrada nas metrópoles da região Sudeste do país, especialmente São Paulo e Rio de Janeiro. Todavia, a partir da segunda metade dos anos 2000, as empresas começaram um processo de dispersão para cidades de menor porte e para a região Nordeste, na procura de uma força de trabalho mais barata e menos organizada sindicalmente, além dos incentivos oferecidos pelos municípios como forma de atrai-las.

Embora esse processo não signifique o abandono das atividades nas grandes metrópoles do Sudeste, que continuam mantendo nesses locais a centralização do controle e os núcleos decisórios, a dispersão das atividades entre cidades menores tem provocado um aumento dos trabalhadores de teleatendimento nesses

15 Instaladores são aqueles trabalhadores responsáveis por instalar os equipamentos de telefonia nas residências e demais locais privados e públicos. 
locais. Isto significa mais uma divisão do trabalho no serviço prestado, agora no interior do território nacional. Esse arranjo denota uma reconfiguração espacial dos serviços que as empresas mantêm, como demonstra Marina Almeida:

As unidades que prestam serviços mais complexos [ficam] em áreas com maior "densidade informacional" (Santos, 1996: 205), isto é, em pontos facilmente conectados com as demais partes do globo. Já as centrais de atendimento (unidades de operação) normalmente se localizam em áreas desvalorizadas, onde os salários pagos aos operadores são menores, as oportunidades de emprego são escassas e um grande contingente de trabalhadores, sobretudo jovens, se submete às condições precárias de trabalho (...) (Almeida, 2014: 2360).

\section{A expansão do trabalho de teleatendimento no Brasil}

O crescimento do número de trabalhadores empregados no teleatendimento é um fenômeno encontrado em diferentes países. No Brasil, a partir da década de 1990, ocorreu uma rápida generalização da utilização de tecnologias, como a informática e a internet; com isso, este tipo de emprego aumentou significativamente. Segundo a Relação Anual de Informações (RAIS) ${ }^{16}$, em 2003, havia 125.154 empregados formais no teleatendimento terceirizado no Brasil; já em 2009, este número chegou a 353.304, perfazendo um crescimento de aproximadamente $190 \%$. Se considerarmos todos os trabalhadores do setor, terceirizados ou contratados diretos, este número é ainda maior.

Os dados da Pesquisa Nacional por Amostra Domiciliar (PNAD) ${ }^{17}$ apresentam um cenário um pouco diferente daquele demonstrado pela RAIS para o ano de 2009. De acordo com eles, havia 372.634 trabalhadores nesse ano. Esses dados (Gráfico 1) demonstram que o emprego no teleatendimento diminuiu em 2009, mas voltou a crescer nos anos seguintes, recuperando-se em 2013, quando atinge 431.900 trabalhadores.

Quando separamos o número de trabalhadores por sexo, observamos que após a diminuição dos empregados no setor, em 2009, a maior parte dos recontratados é mulher, tendo diminuído o número e a proporção de homens no setor até 2014, embora eles voltem a crescer em 2015, quando o número de trabalhadores atinge o total de 450.074 .

16 A RAIS é elaborada pelo Ministério do Trabalho e Emprego. Disponível em: <http://www.rais.gov.br/ sitio/index.jsf>. Acesso em: 10 set. 2019.

17 A PNAD é uma pesquisa amostral, realizada por meio da declaração do trabalhador; já a RAIS é uma declaração obrigatória, prevista em lei, realizada pelos empregadores por meio do sistema do Ministério do Trabalho e Emprego (MTE). 


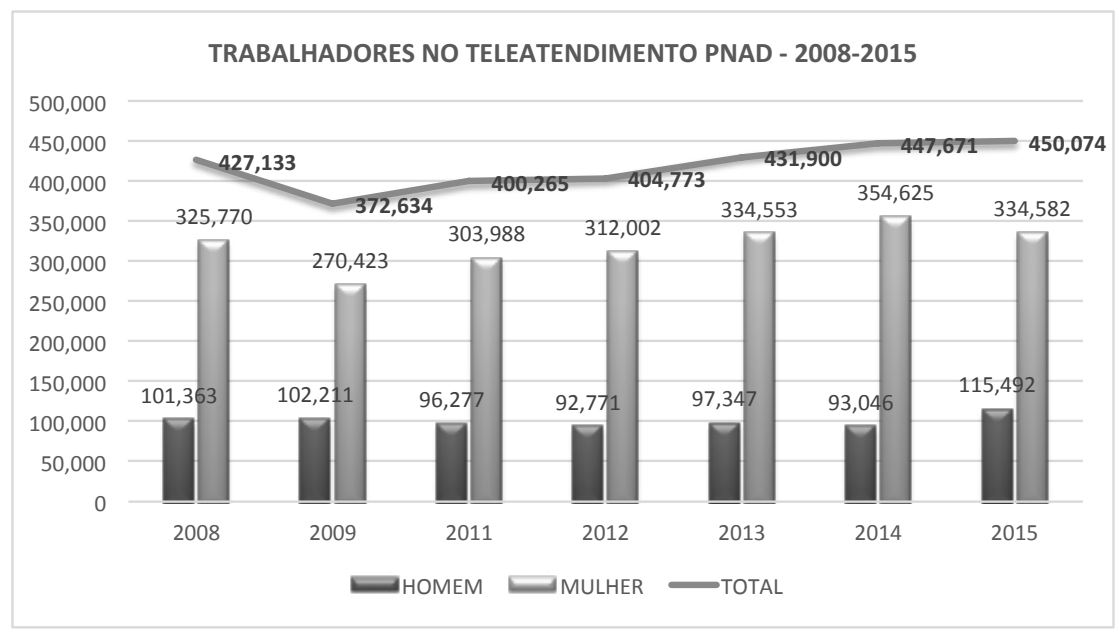

Fonte: PNAD 2008-2015. Elaboração própria.

Ocupação: telemarketing. CBO: 4223

No ano de 2010 a PNAD não foi realizada devido à ocorrência do Censo Demográfico 2010.

Concentrando a análise nos anos mais recentes, observamos que o Ranking das empresas de call center18 estima que 527.288 funcionários formais estavam empregados em empresas de teleatendimento terceirizadas em 2016. Já a estimativa do Sindicato dos telefônicos do Rio Grande do Sul era de que havia 2 milhões de empregados terceirizados e contratados diretos nos mais diferentes setores do telemarketing, em $2017^{19}$.

A enorme diferença entre esses dados coletados entre 2015 e 2017 se deve, provavelmente, não só ao ano da coleta, às distintas metodologias utilizadas na coleta e tratamento dos dados, mas também ao fato de que a PNAD, o Ranking das empresas de call center, bem como o Sindicato devem levar em conta diferentes contratos de trabalho. É possível supor que a grande diferença entre os números encontrados pela PNAD e o Ranking das empresas de call center, por um lado, e o Sindicato dos telefônicos do Rio Grande do Sul, por outro, deva-se ao fato de este último ter acesso a trabalhadores terceirizados e não registrados, mais difíceis de serem captados pela metodologia aplicada pelas outras duas pesquisas. Nesse sentido, a diferença nos dados apresentados pode ser tomada como um indício de uma prática vigorosa de terceirização no setor.

18 Disponível em: <http://ranking.callcenter.inf.br/>. Acesso em: 10 set. 2019.

19 Disponível em: <http://www.extraclasse.org.br/edicoes/2014/o7/call-center-trabalhadores-por-um-fio/>. Acesso em: 10 set. 2019. Ver: <http://www.sinttelrs.org.br/index.php?Itemid=202>. Acesso em: 20 out. 2016. Ver também: <http://g1.globo.com/concursos-e-emprego/noticia/2012/10/telemarketing-emprega-14milhao-no-pais-veja-como-e-o-trabalho-no-setor.html>. Acesso em: 10 set. 2019. 
As estatísticas indicam que ocorreu um crescimento significativo do emprego no setor, mesmo em momentos de aumento do desemprego e diminuição do Produto Interno Bruto (PIB), o que pode demonstrar a capacidade de sustentação econômica das empresas. Considerando esse expressivo crescimento, procuramos verificar como as pesquisas demonstram as condições de trabalho neste setor em um contexto de expansão das empresas e de terceirização do teleatendimento em empresas públicas e privadas.

\section{As condições de trabalho no teleatendimento}

Aqui, chegamos às questões centrais deste texto: quais são as condições de trabalho a que são submetidos os empregados no teleatendimento? Como as tecnologias de comunicação (o computador, a internet de alta velocidade, os softwares de controle do atendimento etc.) determinam os ritmos de trabalho e aumentam os índices de produção? Quais são as exigências contratuais e tácitas do emprego no telemarketing? Que implicações pode ter o processo de relocalização das empresas sobre as condições e remuneração do trabalho?

No teleatendimento, os trabalhadores são empregados em tempo parcial, são submetidos a um ritmo intenso de trabalho e a um controle mediado pelas tecnologias da informação e comunicação. As empresas contratam sobretudo jovens e mulheres, que enfrentam cotidianamente condições extenuantes de trabalho, ainda que possuam uma jornada parcial, com 6 horas e 20 minutos, em média. Estas jovens trabalham seis dias por semana, com uma folga; sofrem constante pressão para aumentar o número de chamadas atendidas/ realizadas por período; estão sob o controle estrito realizado por softwares sobre os quais não possuem qualquer controle; além de receberem baixíssimos salários, os quais as levam, muitas vezes, a acumularem dois empregos e o trabalho doméstico (Venco, 2003; Nogueira, 2006; Braga, 2012; Costa; Costa, 2018).

No Brasil, a indústria do call center possui uma configuração oligopolista ${ }^{20}$, as duas maiores empresas do setor possuem $47 \%$ do total de trabalhadores de teleatendimento, $89 \%$ da força de trabalho está alocada em empresas de grande porte e sete grandes empresas dominam o mercado (Dutra, 2016: 73). As empresas brasileiras são seis vezes mais concentradas que as dos Estados Unidos e catorze vezes mais que as francesas. Estas empresas também oferecem salários muito inferiores quando comparadas a suas congêneres internacionais.

20 As cinco maiores empresas de teleatendimento no Brasil são: Atento, Liq (antiga Contax), Almaviva do Brasil, AeC e Neobpo (Ranking Call Center. Disponível em: <http://ranking.callcenter.inf.br/pesquisa/ detalhe/?empId=100>. Acesso em: 10 set. 2019). 
O oligopólio por elas estabelecido facilita o baixo assalariamento, ainda que 0 montante de capital movimentado seja enorme.

Com efeito, os salários no teleatendimento no Brasil são dez vezes menores que aqueles pagos nos Estados Unidos e três vezes menor que na África do Sul (Braga, 2012: 192). Ao compararmos Brasil e Argentina, dois países da América Latina, observamos que em 2006, o salário médio de um operador de telemarketing estava em U $\$ 240,02^{21}$ no Brasil e U $\$ 700^{22}$ na Argentina, pela mesma jornada de trabalho. Trata-se de uma comparação arbitrária, pois os valores variam de acordo com o posto de trabalho e as condições de vida, além da diferente configuração do setor em cada país. Por exemplo, o fato de que na Argentina uma parte importante do trabalho em telemarketing nesse momento era realizado offshoring, ou seja, por empresas que prestavam serviços para consumidores de empresas localizados em outros países, enquanto que aqui o serviço de telemarketing esteve sempre voltado ao mercado interno, pode significar a concentração de atividades mais complexas no serviço argentino. De todas as formas, a comparação pode contribuir para a compreensão do assalariamento do setor no país.

É preciso considerar também que os salários possuem uma parte importante que é variável, cujo alcance, vinculado ao atendimento de metas, via de regra, excessivas, é bastante difícil. Como explicita Renata Dutra, condicionadas ao cumprimento de uma rígida disciplina, essas metas "são alcançadas por um número mínimo de trabalhadores” (Dutra, 2016: 79).

Haveria que assinalar ainda que, de acordo com os dados da PNAD, a média salarial vem decrescendo quando comparada ao salário mínimo: enquanto, em 2004, a média salarial do país $(\mathrm{R} \$ 556,00)$ era de pouco mais de 2 salários mínimos $(\mathrm{R} \$ 260,00)$, a média salarial de $2016(\mathrm{R} \$ 1.152,63)$ se encontra pouco acima do mínimo ( $\mathrm{R} \$ 937,00)$, aproximadamente 1,3 vezes seu valor. Obviamente, é preciso levar em conta que esse período corresponde a um esforço do governo federal no sentido de recuperar o valor do salário mínimo, o que resultou em um aumento importante. De todas as formas, o comportamento dos salários do setor estaria indicando que ele não acompanhou a recuperação do salário mínimo, aproximando-se cada vez mais do seu valor.

Por outro lado, os dados dos dois últimos anos indicam uma perda do valor real dos salários do setor, que passam de $\mathrm{R} \$ 1.189,08$, em 2014, a $\mathrm{R} \$ 1.152,63$, em

21 Piso salarial da categoria retirado do site: <http://www.pisosalarial.com.br/geral/tabela-salarial-maio-de-2006/> . Acesso em: 20 dez. 2018. Cotação do dólar extraída de <https://www.portalbrasil.net/2006/ indices/dolar/maio.htm>. Acesso em: 10 set. 2019. 
$2016^{23}$. Se considerarmos a diferença salarial entre as empresas situadas no Sudeste e no Nordeste e interior do país e o grande aumento do número de trabalhadores nessas últimas regiões nos últimos anos ${ }^{24}$, é bastante provável que a diminuição da média salarial da categoria esteja relacionada ao atual processo de relocalização das empresas. Alguns achados mais recentes sobre os salários indicam nesse sentido, conforme se pode observar pela pesquisa de Almeida (2014: 2366):

(...) a redução dos custos do trabalho é o fator mais relevante para a instalação das empresas. Nos estados da região Sul do Brasil, a remuneração dos operadores, em dezembro de 2011, estava entre os mais altos do país, ao variar de $\mathrm{R} \$ 828,78$ no Rio Grande do Sul a $\mathrm{R} \$ 898,32$ no Paraná. Já os estados da região Nordeste detinham as menores remunerações. Na Bahia, estado com maior número de operadores da região, o salário era de $\mathrm{R} \$ 687,81$, diminuindo para $\mathrm{R} \$ 638,41$, em Pernambuco, menor remuneração dentre os estados brasileiros (MTE/CAGED, 2013).

No mesmo sentido apontam os dados a seguir, registrados na mesma pesquisa de Marina Almeida (2014: 2361):

O salário médio de um operador na cidade de São Paulo, em 2011, foi de $\mathrm{R} \$ 849,72$, enquanto na cidade de Ourinhos (SP), no interior do estado foi de $\mathrm{R} \$ 679,15$ e em Caruaru, no agreste pernambucano, de apenas $\mathrm{R} \$ 581,27$ (MTE/CAGED, 2013).

Esses dados indicam um processo em curso de diminuição dos salários da categoria, provocado pela imigração das empresas para cidades não metropolitanas e para o Nordeste, ocorrido sobretudo nos últimos anos. Os salários dos trabalhadores terceirizados pelas empresas de call center são ainda mais baixos, como mostra a pesquisa de Guilherme Stein, Eduardo Zylberstajn e Hélio Zylberstajn (2017), analisando os dados da RAIS (2007-2014) dos trabalhadores do setor.

Vale observar também que, além dos salários baixos, os trabalhadores enfrentam problemas com a autorização de férias anuais, banco de horas e erros de pagamento dos salários (Freitas, 2010: 46-47).

A jornada de trabalho diária contempla o horário de serviço e pausas para banheiro, alimentação e descanso. No momento em que estão realizando o atendimento, o controle alcançado pelo software é múltiplo:

23 Valores de 2014 deflacionados de acordo com os dados para 2016.

24 De acordo com Ana Carmen Moraes (2017: 6), o atual processo de reterritorialização do setor indica um forte "aumento da participação da região Nordeste, que se consolida na segunda posição, concentrando, em $2015,23,4 \%$ do total de operadores de telemarketing do país". 
(...) registro de cada atendimento pelos próprios operadores no sistema eletrônico específico e escutas telefônicas dos atendimentos em tempo real pelos trabalhadores da "monitoria". Semanalmente são emitidas avaliações individuais que indicam a qualidade do atendimento de acordo com os parâmetros das empresas: rapidez na identificação da demanda do cliente, dicção, empatia, tom de voz, atenção/interesse, tempo médio de atendimento (TMA), adequação ao script, entre outros (Oliveira; Rezende; Brito, 2006).

As pausas, autorizadas pelos supervisores com base no controle digital do horário dos operadores, são curtas e insuficientes para as atividades previstas. Muitos trabalhadores utilizam o tempo das pausas para manter o nível de produção e cumprir as metas estabelecidas. As pesquisas não relatam a realização sistemática de exercícios (ginástica laboral) e outras técnicas para a prevenção de problemas de saúde.

Os baixos salários favorecem a rotatividade entre os trabalhadores. Os operadores de telemarketing aparecem entre as dez ocupações que mais desligaram trabalhadores entre 2011 e 2012 (DIEESE, 2014), em um contexto de forte expansão do setor, como observamos no item anterior. O estudo do DIEESE aponta ainda que as taxas de rotatividade do setor mantiveram-se acima de $90 \%$ de 2007 a 2013, tendo alcançado 109,5\% nesse último ano, um valor que mostra "sua grandeza quando comparado ao setor de serviços, cuja taxa de rotatividade fica em média em 50\%, ou ao mercado de trabalho formal de uma forma geral, cuja média global foi de 63,7\% em 2013" (Dutra, 2016: 79). Os altos índices de rotatividade no emprego são favorecidos pelo tipo de trabalho realizado. A telemática possibilitou uma maior mecanização do trabalho do atendente, que segue as determinações de softwares desenvolvidos especificamente para padronizar o atendimento e controlar o conteúdo do trabalho. Os softwares diminuem as margens de ação autônoma dos trabalhadores ao reduzir o conteúdo do trabalho à interação com suas orientações. Com isso, a empresa de teleatendimento torna-se menos dependente do conhecimento técnico do operador, que recebe treinamentos antes de assumir sua Posição de Atendimento (PA) e depois que estão empregados, conforme a mudança nas operações de atendimento (Braga, 2012; Venco, 2003).

As empresas exigem, em geral, o Ensino Médio como pré-requisito para os operadores, mas não há nenhuma qualificação específica para a admissão. A qualificação do trabalhador no teleatendimento ocorre em serviço, nos treinamentos e na aprendizagem com os companheiros de trabalho mais experientes. Hermes Costa e Elizardo Costa (2018: 121) realizaram uma pesquisa quantitativa 
com 155 teleoperadores de uma mesma empresa, na qual constataram que apenas $20 \%$ dos consultados tinha alguma frequência universitária (Ensino Superior incompleto ou completo), o restante chegava ao Ensino Médio completo. São oferecidos scripts pré-definidos aos trabalhadores, sem espaço para criações, reduzindo, com isso, "a livre atuação dos trabalhadores no espaço 'existente' entre o trabalho prescrito e o realizado" (Venco, 2003: 21). Os treinamentos fornecidos pelas empresas são, em geral, voltados aos procedimentos do atendimento e ao desenvolvimento da expressão pela voz.

Os trabalhadores ocupam uma Posição de Atendimento reduzida a um computador, fones de ouvido, microfone, mesa e cadeira. O teletrabalho ocorre neste espaço-tempo, no qual o operador permanece sentado e limitado ao script, o que favorece o controle do seu trabalho (Souza, 2012). O fluxo de ligações é ininterrupto, os espaços "vagos" são preenchidos rapidamente por novas ligações, constantemente supervisionadas.

Além do controle exercido pelo software, que emite informações sobre o número de atendimentos, há o controle realizado por um supervisor direto, que vigia e emula constantemente os operadores para garantir o cumprimento de metas estabelecidas.

O software expõe em tempo real os horários, os resultados, as ações de cada trabalhador, possibilitando o estabelecimento de metas precisas, e o supervisor garante corporalmente seu cumprimento. Os trabalhadores são incentivados a competir entre si, bem como são formadas equipes que disputam os rankings internos, por meio dos quais as empresas concedem pequenos prêmios e homenagens (Braga, 2012; Freitas, 2010).

Os teleoperadores recebem bonificações de acordo com o cumprimento dessas metas. Além do salário básico, recebem pela realização de metas individuais, metas da equipe e metas da operação como um todo. É estabelecido um ambiente de intensa competição, que favorece a solidariedade entre membros de uma mesma equipe ao mesmo tempo em que incentiva a competição individual (Braga, 2012: 194).

Esse ambiente de extrema competitividade se baseia na contratação de jovens mulheres sem experiência anterior de trabalho ou no primeiro emprego, bem como na alta rotatividade dos trabalhadores. Ruy Braga (2012) sugere que o ciclo de emprego do teleoperador - contratação/ inexperiência; proficiência/ satisfação residual; produtividade; rotinização/ adoecimento; demissão; seguro-desemprego - mantém-se pela entrada recorrente de novos trabalhadores. Segundo o autor, o ciclo tem a duração média de 20 a 24 meses. "É comum observar [que], em um intervalo de seis a oito meses, a base da central 
de atendimento é toda renovada" (Barreto, citado por Braga, 2012: 196). Lailah Vilela e Ada Assunção apontam que na empresa de telemarketing na qual realizaram pesquisa, em 2003, 96\% do efetivo de trabalhadores era substituído a cada dois anos, uma média de substituição do efetivo de $2 \%$ ao mês (Vilela; Assunção, 2004: 1071).

Renata Dutra (2016: 80-81) refere-se a um padrão específico de gestão, "generalizado no setor, que se pauta em rigor disciplinar e excessivo número de advertências e suspensões que são sucessivamente aplicadas pelas empresas, inclusive por razões banais", levando muitos trabalhadores a optar por demissão, como forma de evitar a justa causa.

Vale lembrar ainda que, em virtude do fato de que as empresas são terceirizadas, os trabalhadores do setor são submetidos também ao controle exercido pela empresa tomadora de serviços, para a qual trabalha a empresa que os contratam, a qual sói exigir rígidos critérios de produtividade e qualidade e acompanha os atendimentos oferecidos em tempo real (Venco, 2009).

Essas difíceis condições de trabalho levam comumente os trabalhadores ao adoecimento. Com base na aplicação de questionários com trabalhadores do setor, Ruy Braga (2012) aponta que o adoecimento no teletrabalho está relacionado às seguintes situações, relatadas recorrentemente pelos operadores:

(...) treinamento inadequado, estresse decorrente das metas, negligência com a ergonomia e temperatura do ambiente de trabalho, exíguos intervalos durante a jornada, folgas insuficientes, forte (...) enquadramento do teleoperador ${ }^{25} \mathrm{e}$ intensificação dos ritmos de trabalho proporcionados pelo permanente processo de renovação tecnológica (p.191).

As doenças mais comuns enfrentadas pelos trabalhadores são: lesão por esforço repetitivo (LER), calos nas cordas vocais, depressão, infecções urinárias ${ }^{26}$, vertigens, zumbidos nos ouvidos e surdez (Venco, 2003; Nogueira, 2006; Braga, 2012; Bomfim, 2016). Na pesquisa realizada por Ruy Braga, 62\% dos operadores consultados indicaram comprometimento da saúde (Braga, 2012: 190). Tais Freitas (2010) apresenta registros de trabalhadores que depois de um quadro de esgotamento físico e mental tentaram suicídio (Freitas, 2010: 49-50).

Os problemas psicológicos decorrentes do ritmo e intensidade do trabalho são bastante relatados pelos teleatendentes, como constatado pela pesquisa de

25 Os denominados tempos mortos no trabalho diminuem muito com o estrito controle sobre o trabalhador, que o autor denomina "enquadramento do trabalhador".

26 Os trabalhadores possuem, em média, duas pausas de cinco minutos para utilizar o banheiro. Para cumprir as metas, muitos deixam de utilizá-las, o que favorece o desenvolvimento de sérios problemas de saúde. 
Lailah Vilela e Ada Assunção (2004). A recente pesquisa de Laís di Bella Rabello et al. (2018) relata o caso de uma teleatendente que passou por perícia na justiça do trabalho no decorrer de um processo judicial contra a empresa na qual trabalhava por assédio moral e negligência de doenças psicossomáticas decorrentes das condições de trabalho. $\mathrm{O}$ estudo revela uma relação causal entre adoecimento psicossomático e a organização do trabalho, demonstrando como cefaleia, náuseas, tonturas, intolerância a ruídos podem evoluir para doenças mais graves que comprometem as capacidades físicas dos trabalhadores.

A barreira que separa o teleatendente do cliente é virtual, basta pulsar o botão e desligar para que o diálogo seja interrompido. No entanto, o teleatendente não pode desligar, deve seguir rigorosamente o script e continuar atendendo um cliente que, muitas vezes, sente-se à vontade para reagir de forma desrespeitosa, protegido pela impessoalidade do telefone. As pesquisas de Vilela e Assunção (2004) mostram que "a empresa depende do esforço mental dos teleatendentes para diminuir os efeitos da impossibilidade de garantir a satisfação do cliente nos tempos previstos por suas metas" (p. 1076). Ana Bomfim (2016) constata em sua pesquisa que o teleatendente está situado entre a exigência de uma "saúde perfeita”, em especial no que diz respeito à voz e à execução de um trabalho permeado por forte controle disciplinar e emocional. Impedido de cumprir o prescrito e obrigado a suportar o cliente insatisfeito com os serviços da empresa, o teleatendente pode ser levado ao esgotamento mental.

\section{Relações de gênero}

De acordo com os dados coletados por nós, aproximadamente $70 \%$ de todo contingente de empregados é composto por mulheres ${ }^{27}$. A ampliação do emprego formal no Brasil, na década de 2000, possibilitou que muitas mulheres que trabalhavam na informalidade, parte delas como empregadas domésticas, fossem empregadas no teleatendimento. Esta passou a ser uma possibilidade viável para as jovens trabalhadoras que buscavam inserção no trabalho formal.

Seguindo a tendência da maioria dos países, a participação das mulheres no mercado de trabalho brasileiro aumentou consideravelmente a partir dos anos 1980. Segundo a PNAD, o número de mulheres inseridas na estrutura ocupacional vem aumentando progressivamente desde então: em 2001, a participação feminina na População Economicamente Ativa era de 41\%; em 2015, esse

27 Ver <http://www.callcenter.inf.br/online/24094/mulheres-sao-maioria-no-telemarketing/imprimir.aspx $>$. Acesso em: 20 dez. 2018. 
percentual não se alterou substancialmente, atingindo aproximadamente $42 \%$, ainda que em anos anteriores, como 2013, tenha alcançado $45 \%{ }^{28}$.

Muitas profissões e ocupações foram transformadas buscando incorporar a força de trabalho das mulheres; a maior parte delas são ocupações subordinadas a níveis hierárquicos masculinos, relacionadas a estereótipos femininos como a afetividade, o cuidado, a flexibilidade. No caso do teleatendimento, as mulheres são valorizadas pela paciência, pela voz suave, pelo "jeitinho" no trato com os clientes (Venco, 2003; Nogueira, 2006). Trata-se de um fator de discriminação das mulheres e aquelas que não se enquadram neste perfil são rapidamente substituídas.

O trabalho em tempo parcial é considerado estratégico para as mulheres devido às necessidades decorrentes do trabalho doméstico e com os filhos. De acordo com o Censo Demográfico IBGE 2010, 37,3\% das famílias brasileiras são chefiadas por mulheres. Ainda que a maior parte das famílias não seja monoparental, elas são geralmente responsabilizadas pelo trabalho doméstico. Para muitas, o trabalho no teleatendimento garante uma certa estabilidade e os horários permitem conciliar os dois tipos de trabalho ou mesmo dois tipos de vínculo empregatício.

$\mathrm{O}$ fato de $\mathrm{o}$ teleatendimento ocorrer mediado pelo telefone e prescindir das características corporais dos trabalhadores favorece também a contratação de grupos sociais que não se enquadram em perfis sociais privilegiados pela maior parte do setor de serviços que pressupõem contato direto com o cliente. Dessa forma, além das mulheres, outros grupos sociais mais discriminados, como homossexuais (lésbicas, gays), transexuais, negras, obesas, deficientes físicos, punks etc., são mais facilmente incorporados pelo teleatendimento (Venco, 2009; Freitas, 2010). São trabalhadores que geralmente encontram dificuldades para se inserir em termos ocupacionais, devido ao preconceito a que estão sujeitos. No entanto, isto não significa que estejam livres de preconceitos e da discriminação no interior das empresas, como pudemos observar na pesquisa de Tais Freitas (2010: 43).

Acolher os grupos sociais mais marginalizados, como as mulheres negras, homossexuais, deficientes etc., faz dessas empresas lugares "menos" discriminatórios no momento da contratação. Contudo, empregar grupos tradicionalmente excluídos do mercado formal de trabalho também significa praticar menores salários e submeter os trabalhadores a maiores exigências. A alta produtividade dos empregados associada ao baixo custo da força de trabalho torna

28 Disponível em: <http://www.sidra.ibge.gov.br>. Acesso em: 10 set. 2019. 
o teleatendimento um dos serviços mais rentáveis do setor, sendo aquele que oferece os menores salários. As saídas mais comuns para enfrentar essas condições de trabalho parecem ser individuais, por meio de licenças prolongadas do trabalho, que podem significar um não retorno; busca por tratamentos físicos e mentais; ingresso em uma faculdade etc. No entanto, como esses trabalhadores enfrentam coletivamente os problemas decorrentes das condições de trabalho?

\section{Sindicalismo}

A organização coletiva dos trabalhadores do telemarketing parece ser bastante dificultada pelo rígido controle exercido sobre o trabalho. Ruy Braga (2012) afirma que as entrevistas realizadas com sindicalistas do setor em São Paulo mostram que há uma perseguição sistemática dos trabalhadores que começam a se aproximar do sindicato e exercer alguma influência sobre os colegas. Este tipo de ação das empresas fragiliza a organização sindical, pois o trabalhador é muito pressionado e a base sindical não acumula experiências de organização coletiva.

O autor aponta também que a privatização das empresas de telecomunicações desorganizou os sindicatos tradicionais desta categoria, como ocorreu com o Sindicato dos Trabalhadores em Telecomunicações no Estado de São Paulo (Sintetel-SP):

(...) a representação dos teleoperadores passou a ser disputada com outro sindicato, surgido em 1992, o Sintratel (Sindicato dos Trabalhadores em Telemarketing de São Paulo), que reivindicou a representação dos trabalhadores em telemarketing do município de São Paulo e de sua região metropolitana, e por isso está em permanente litígio judicial com o Sintetel, que representa os trabalhadores do setor de telecomunicações de todo o estado de São Paulo (Braga, 2012: 201).

Situação semelhante é assinalada pelo estudo de Mônica Cavaignac (2013), o qual relata que, a partir de 2005, no Ceará, também ocorreu uma disputa entre o Sindicato dos Trabalhadores em Telecomunicações (SINTTEL) e o Sindicato dos Trabalhadores em Telemarketing (SINTRATEL) pela base composta pelos trabalhadores do telemarketing.

Segundo Ruy Braga (2012), as transformações ocorridas na reorganização do sindicalismo das telecomunicações promoveram também transformações na estratégia sindical do setor, que passou de uma atuação mais combativa para outra mais defensiva dos empregos e salários e mais assentada no oferecimento de serviços aos associados, como convênios médicos, educação profissionalizante, festas etc. 
Os estudos demonstram uma vigorosa ação das empresas no sentido de desmobilizar os trabalhadores. De acordo com Marina Almeida (2014), além das iniciativas claramente antissindicais, como as perseguições aos trabalhadores mais organizados, elas se utilizam também da flexibilidade da tecnologia, que permite a transferência de chamadas de uma unidade a outra em caso de greves e mobilizações (Almeida, 2014).

Apesar das dificuldades da organização sindical, a pesquisa realizada por Ruy Braga (2012: 208-2010) mostra que as greves no setor aumentaram após 2005. Antes desse período, o autor registrou apenas uma greve em 2000, na empresa Quatro/A, em que os trabalhadores reivindicavam o retorno do vale alimentação, substituído por um lanche fornecido pela empresa. A partir de 2005, as greves foram além e passaram a reivindicar participação nos lucros e resultados (PLR), creche, reajuste salarial, redução da jornada de trabalho, reajuste do vale alimentação etc. Dentre elas, estão: greve na Atento, na região do ABC, em 2005 (mais de nove dias); greve na CSU Card System, na unidade Santo André e São Paulo, em 2008 (dois dias de greve); greve na Atento, unidade Marechal Deodoro, em 2006 (quarenta dias).

Na mesma direção, Mônica Cavaignac (2013) relata uma importante greve dos trabalhadores do telemarketing de uma grande empresa do ramo na cidade de Fortaleza (CE), em 2007, que se estendeu por um mês. As principais reivindicações eram salariais e por melhores condições de trabalho, denunciando a pressão para o cumprimento de metas e as restrições de paradas para o uso do banheiro.

A autora relata que muitos dos empregados da empresa não aderiram à greve, pois haviam entrado recentemente no emprego e caso fossem demitidos não poderiam solicitar o seguro desemprego. Além disso, a empresa reagiu de maneira muito violenta: utilizou-se de policiamento ostensivo, permitindo que a polícia entrasse no local de trabalho; fez ameaças de demissões por meio de telegramas; e contratou outros trabalhadores para substituir os grevistas durante o movimento reivindicatório.

Nos últimos anos, outras greves ocorreram no setor, como a dos teleoperadores da Atento e Contax, no Rio de Janeiro, em 2014, que mobilizou cerca de quinze mil trabalhadores ${ }^{29}$; a dos trabalhadores da Contax, em Recife, em 2013, e em Belo Horizonte e Porto Alegre, em 2014 $4^{30}$; a dos teleoperadores de Forta-

29 Disponível em: <http://extra.globo.com/noticias/economia/operadores-de-telemarketing-entram-emgreve-no-rio-de-janeiro-14854608.html>. Acesso em: 20 out. 2017 [página retirada da internet em 2018]. Os trabalhadores reivindicavam aumento do piso salarial, redução das jornadas, fim das metas abusivas, etc. 
leza, em 2011 ${ }^{31}$; dentre outras. Para Ruy Braga (2012: 2012), a despeito das dificuldades impostas à organização coletiva dos trabalhadores, há um movimento em marcha, ainda que não seja forte o suficiente para garantir muitas de suas reivindicações.

As pesquisas de Ruy Braga (2012) e Mônica Cavaignac (2013) demonstram que, apesar dos muitos obstáculos que dificultam a organização dos trabalhadores - como o medo de perder o emprego; as pressões exercidas por supervisores; o assédio moral por parte da empresa; a divisão entre os sindicatos; a rotatividade de empregados -, os trabalhadores se organizaram a ponto de promover greves e negociar as reivindicações, o que é fundamental para a garantia de direitos conquistados e para a conquista de novos.

Além disso, vários estudos (Venco, 2009; Braga, 2009; Moraes, 2017; Dutra, 2017) apontam para uma resistência cotidiana menos explícita realizada pelos trabalhadores, seja nos locais de trabalho seja em outros locais, como pontos de ônibus, grupos virtuais, grupos de lazer etc. No primeiro caso, predominam o desrespeito às regras; burlas ao sistema, como derrubadas intencionais; uso de pausas seguidas; conversas com colegas na hora do almoço e de troca de turnos. Já no segundo caso, observam-se denúncias judiciais contra as empresas; reclamações aos sindicatos de erros nas verbas rescisórias; desabafos nas paradas de ônibus e redes virtuais.

\section{Considerações finais}

As pesquisas consultadas mostram que ocorreu uma expansão significativa do teleatendimento após as privatizações das telecomunicações no Brasil. O setor de call center cresceu juntamente com as terceirizações do atendimento de clientes de grandes empresas, como as de telefonia fixa e móvel, os bancos, lojas de departamento etc., acompanhando o processo de formação de cadeias globais de valor.

A organização deste setor está fortemente relacionada com as transformações operadas pela reestruturação produtiva e pela inserção da tecnologia da informação e comunicação no processo de trabalho. Trata-se de um trabalho completamente racionalizado, controlado por meio de Tecnologias da Informação e Comunicação (TICs). Selma Venco (2009) e Ruy Braga (2012) destacam que as TICs possibilitaram a ampliação da "taylorização" do processo de

31 Disponível em: <http://site.sintratelceara.com.br/?option=com_content\&view=article\&id=8:trabalhadoresde-telemarketing-da-sitelcoelce-realizam-greve-nesta-3-feira\&catid=11:noticias\&Itemid=313>. Acesso em: 20 dez. 2018 . 
trabalho, o que significa que os trabalhadores são submetidos a múltiplos controles precisos. $\mathrm{O}$ controle permite o estabelecimento de metas, assim como a verificação de lacunas e tempos ociosos no atendimento, que podem diminuir a produtividade do trabalho e o rendimento das empresas.

O setor de call centers nasce de um processo radical de desverticalização das empresas $^{32}$, em que a terceirização dá lugar ao surgimento de um novo setor. Referimo-nos ao fato de que, nesse processo de desverticalização, as empresas terceirizam atividades antes realizadas em seu âmbito, que passam a ser desenvolvidas por outras empresas, as quais acabam conformando um novo setor de atividade. Esse processo, além de promover desqualificação da força de trabalho, submete os trabalhadores a um duplo controle.

A desqualificação ocorre porque, no processo de terceirização, as atividades que se deslocam são, em geral, as menos sofisticadas em termos tecnológicos, que exigem, portanto, menor qualificação para serem realizadas. No caso do setor de call center, valeria observar ainda o alerta de Miriam Glucksmann (2004), por exemplo, para as atividades de venda de produtos. De acordo com a autora, a terceirização da atividade vem acompanhada de uma desqualificação do serviço prestado, na medida em que quando a atividade se realiza em um call center localizado no interior da empresa que oferece o produto, os teleoperadores se vinculam com outras etapas do processo produtivo, à jusante, com a produção, o marketing e a publicidade, e à vazante, com a distribuição, a entrega e o cliente final. Todavia, quando o call center é tercerizado, a densidade e extensão das conexões variam completamente, com consequências sobre a qualidade do trabalho (Del Bono; Leite, 2016).

Já o duplo controle ocorre porque, além do forte controle exercido pela supervisão da empresa empregadora, os trabalhadores estão sujeitos ao controle da empresa tomadora dos serviços que, conforme alertado anteriormente, consegue acompanhar os atendimentos em tempo real, pressionando sempre por mais qualidade e produtividade dos serviços prestados.

Nesse contexto, os trabalhadores são submetidos a forte pressão para superar constantemente sua produtividade. $\mathrm{O}$ trabalho é realizado em frente a um computador conectado ao sistema da empresa, que fornece todas as informações necessárias para a realização da operação. $O$ sistema da empresa controla o envio das chamadas, que chegam ao operador ininterruptamente. Iniciada a chamada,

32 O processo de desverticalização das empresas consiste na externalização de atividades para fora da empresa e na concentração do processo produtivo naquelas atividades que são centrais na produção de uma determinada mercadoria ou serviço. Esse processo, que impacta todas as áreas de atividade das empresas, é uma tendência generalizada nos dias atuais. 
o operador tem um tempo médio para realizar o atendimento e se manter dentro da meta da empresa. $\mathrm{O}$ trabalhador é controlado durante todo o tempo em que está dentro da empresa, quando chega, utiliza o banheiro, faz uma refeição. $\mathrm{O}$ sistema calcula os minutos que cada trabalhador utiliza, pode escutar cada atendimento realizado e sugere metas sempre maiores a serem atendidas [Freitas (2010); Nogueira; Bastos (2009); Oliveira (2009); Souza (2012)].

As condições de trabalho têm levado muitos teleoperadores ao adoecimento. As pesquisas mostram que são recorrentes os relatos de doenças ocasionadas pelo excesso de trabalho, como lesão por esforço repetitivo, calos nas cordas vocais, problemas na coluna, dores de cabeça decorrentes da pressão dos fones de ouvido, depressão, infecções urinárias, vertigens, zumbidos nos ouvidos e surdez. A rápida aparição destes problemas é considerada nas pesquisas como elemento que pode ajudar a compreender a alta rotatividade de trabalhadores no setor (Venco, 2003; Vilela; Assunção, 2004; Nogueira, 2006; Oliveira, 2009; Braga, 2012).

É nesse contexto que se pode compreender que nem mesmo o trabalho com carteira assinada - exercido sob várias estratégias empresariais para diminuir a rotatividade, como bônus, premiações, financiamento - se apresenta como alternativa interessante de inserção para essa parcela da classe trabalhadora. Em função dos baixos salários e das difíceis condições de trabalho, o emprego é quase sempre encarado como temporário, muitas vezes associado a um período de estudos em nível superior ou à maternidade. Para muitos, ele é um emprego provisório, em especial para as mulheres estudantes (Venco, 2003 e 2009), ou simplesmente uma transição a formas mais atrativas de inserção, ainda que muitos trabalhadores retornem a ele depois de um período de desemprego em que outras alternativas se mostram pouco viáveis (Moraes, 2017).

A falta de perspectiva de continuidade também é um dos fatores que permite entender a frágil organização sindical do setor. Além disso, as pesquisas consultadas mostram uma forte perseguição das empresas aos trabalhadores que se aproximam dos sindicatos e uma intensa disputa entre os sindicatos pela base dos trabalhadores do teleatendimento. Ainda assim, os trabalhadores têm demonstrado resistir de forma organizada às condições de trabalho por meio de greves e paralisações.

Os estudos discutidos demonstram que a análise do trabalho no teleatendimento pode contribuir para a compreensão da organização do trabalho na contemporaneidade após a generalização da reestruturação da produção em função das crises cíclicas do capitalismo e das mudanças na base tecnológica da produção de mercadorias. Nesse processo, o teleatendimento adquiriu uma importância no setor de serviços, no mercado de trabalho brasileiro e no amplo processo de terceirização de atividades operado pelas grandes empresas e pelo Estado. Por 
outro lado, o esforço de analisar o setor na sua relação com o território e o movimento de relocalização das empresas nos permite compreender o movimento do capital na busca de vantagens comparativas, especialmente aquelas relacionadas ao baixo custo do trabalho, ao lugar que o país vem ocupando na nova divisão internacional do trabalho, bem como ao lugar ocupado pelas diferentes regiões e cidades do país na configuração que o setor vem adquirindo em nível nacional.

\section{Referências}

ALMEIDA, Marina. Das centrais de atendimento aos Contact Centers: uso e reprodução do desenvolvimento geográfico desigual brasileiro. Anais do VI Congreso Iberoamericano de Estudios Territoriales y Ambientales, São Paulo, 8 a 12 de setembro de 2014, pp. 2355- 2377.

Redes corporativas e incentivos territoriais: a dispersão dos contact centers para as cidades médias brasileiras. In: Boletim Campineiro de Geografia, Campinas, v. 3, n. 3, 2013, pp. 430-448.

ANTUNES, Ricardo; BRAGA, Ruy (org.). Infoproletários: degradação real do trabalho virtual. São Paulo, Boitempo, 2009.

BRAGA, Ruy. A política do precariado: do populismo à hegemonia lulista. São Paulo, Boitempo, Universidade de São Paulo, Faculdade de Filosofia, Ciências e Letras, 2012.

BOMFIM, Ana Soraya Vilasboas. Entre a voz e o ouvido: o trabalho emocional e os impactos para a saúde dos trabalhadores do teleatendimento, o telemarketing, em Salvador. Dissertação de Mestrado, Universidade Federal da Bahia. UFBA Salvador, 2016.

CAVAIGNAC, Mônica Duarte. As estratégias de resistência dos operadores de telemarketing frente às ofensivas do capital. Katályses, Florianópolis, v. 16, n. 2, jul./dez. 2013, pp. 155-164.

. Relações de trabalho e relações no trabalho na lógica capitalista contemporânea: um olhar sobre atendentes do call center de uma empresa de telecomunicações. Tese de Doutorado, Sociologia, Universidade Federal do Ceará. UFC - Fortaleza, 2010.

CAVALCANTE, Sávio. O setor de telecomunicações no Brasil: tendências da prestação de serviços e da situação do trabalho na década de 2000. ANTUNES, Ricardo (org). Riqueza e miséria do trabalho no Brasil III. São Paulo, Boitempo, 2014.

. Sindicalismo e privatização das telecomunicações no Brasil. São Paulo, Expressão Popular, 2009.

COSTA, Hermes Augusto; COSTA, Elizardo Scarpati. Trabalho em call centers em Portugal e no Brasil: a precarização vista pelos operadores. Tempo Social, v. 30, n. 1, pp. 105-127, 2018. 
DEL BONO, Andrea; LEITE, Marcia. El impacto de la tercerización y la deslocalización em el trabajo del telemarketing. Uma comparación entre Argentina y Brasil. Cuadernos del Cendes, Venezuela, año 11, n. 93, 2016, pp. 15-34.

. Deslocalización extraterritorial de empleos del sector servicios. Sentidos y transformaciones del trabajo. Sociología del Trabajo, nueva época, España, n. 56, invierno de 2006, pp. 3-32.

DIEESE. Rotatividade e políticas públicas para o mercado de trabalho. Departamento Intersindical de Estatística Estudos Socioeconômicos. São Paulo, DIEESE, 2014.

DUTRA, Renata Queiroz. Trabalho, regulação e cidadania: a dialética da regulação social do trabalho em call centers na Região Metropolitana de Salvador. Tese de doutorado, Direito, Universidade de Brasília. Direito - UnB, 2017.

DUTRA, Renata. Call Centers no Brasil: uma vitrine do mundo do trabalho após eventual aprovação do PLC $\mathrm{n}^{\circ}$. 30/2015. In: TEXEIRA, Marilane Oliveira; ANDRADE, Hélio Rodrigues; COELHO, Elaine D’Ávila (orgs.). Precarização e terceirização. Faces da mesma realidade. São Paulo, Sindicato dos Químicos-SP, 2016, pp. 69-90.

FILGUEIRAS, Vitor Araújo; CAVALCANTE, Sávio Machado. Terceirização: debate conceitual e conjuntura política. Revista da ABET, Paraíba, v. 14, n. 1, 2015.

FREITAS, Gabriela Oliveira; GODÖI-DE-SOUSA, Edileusa. Recrutamento, seleção, desenvolvimento e motivação: uma análise a partir da percepção do profissional operador de telemarketing. Revista Tecer, v. 11, n. 20, 2018.

FREITAS, Tais Viudes. Entre o tempo da produção e o da reprodução social: a vida das teleoperadoras. Dissertação Mestrado, Sociologia, Universidade Estadual de Campinas. IFCH - Unicamp, 2010.

GEREFFI, Gary; KORZENIEWICZ, Miguel. Commodity chains and global capitalism. Westport Connecticut, London: Praeger Paperback, 1993.

GLUCKSMANN, Miriam. Call configuration: varieties of call centre and divisions of labour. Work, employment and society, v. 18, n. 4, 2004, pp.795-811.

. Formations, Connections and Divisions of Labour. Sociology, v. 43, n. 5, 2009, pp. $878-895$.

HONORATO, Antônio Edson Oliveira; DE OLIVEIRA, Agostinha Mafalda Barra. Estudo de satisfação no trabalho de atendentes de telemarketing. Administração de Empresas em Revista, Curitiba/PR, v. 18, n. 19, 2018, pp. 49-72.

KREIN, José Dari; GONÇALVES, José Ricardo. O impacto das mudanças tecnológicas do setor terciário sobre as relações de trabalho no Brasil, na década de 9o. Trabalho completo em anais. Anais da ANPOCS, 2004. Disponível em: <http://www.anpocs.org/ portal/index.php?option $=$ com_docman\&task $=$ doc_view\&gid $=3871 \&$ Itemid $=318>$. Acesso em: 20 de out. 2017. 
LIMA, Jacob. Negócios da China: a nova industrialização do Nordeste. Novos Estudos Cebrap, São Paulo, n. 49, 1997, pp. 141-58.

MARCELINO, Paula; CAVALCANTE, Sávio. Por uma definição de terceirização. Caderno CRH, v. 25, n. 65, 2012, pp. 331-346. Disponível em: <http://www.scielo.br/ pdf/ccrh/v25n65/v25n65a10.pdf>. Acesso em: 10 set. 2019.

MICHELI, Jordy. Call centers: la relación dinâmica entre TIC y sociedade de la información. Proceedings of the 8th CPR LATAM CONFERENCE, Bogotá, May 30-31st, 2014, pp. 1-7.

MICHELI, Jordy. El sector de call centers: estructura y tendências. Apuntes sobre la situación de México. Frontera Norte, v. 24, n. 47, enero-junio de 2012, pp. 156-160.

MORAES, Ana Carmen. De telefonista a atendente de telemarketing: resistências e ação sindical na Paraíba. Anais do $18^{\circ}$. Congresso Brasileiro de Sociologia, 26 a 29 de julho de 2017, Brasília, DF.

NOGUEIRA, Arnaldo Mazzei; BASTOS, Fabrício Cesar. O desenho do trabalho assalariado em empresas fidelizadoras da indústria de call centers no Brasil. In: ANTUNES, Ricardo; BRAGA, Ruy (org.). Infoproletários: degradação real do trabalho virtual. São Paulo, Boitempo, 2009.

NOGUEIRA, Claudia Mazzei. O trabalho duplicado: a divisão sexual no trabalho e na reprodução: um estudo das trabalhadoras do telemarketing. São Paulo, Expressão Popular, 2006.

NORAT, Rafael Câmara. O assédio moral e a precarização do trabalho: repercussões sobre a saúde do trabalhador de telemarketing. Dissertação de mestrado, Serviço Social, Universidade Federal da Paraíba. UFPB - João Pessoa, 2018.

OLIVEIRA, Simone; REZENDE, Marcello Santos; BRITO, Jussara. Saberes e estratégias dos operadores de telemarketing frente às adversidades do trabalho. Revista Brasileira de Saúde Ocupacional, v. 31, n. 114, 2006, pp. 125-134.

OLIVEIRA, Sirlei M. Os trabalhadores das centrais de teleatividades no Brasil: da ilusão à exploração. In: ANTUNES, Ricardo; BRAGA, Ruy (org.). Infoproletarios: degradação real do trabalho virtual. São Paulo, Boitempo, 2009.

RABELO, Laís Di Bella Castro; SILVA, Julie Micheline Amaral; LIMA, Maria Elizabeth Antunes. Trabalho e adoecimento psicossomático: reflexões sobre o problema do nexo causal. Psicologia: Ciência e Profissão, v. 38, n. 1, 2018, pp. 116-128.

ROSENFIELD, Cinara; ALVES, Daniela. Teletrabalho. In: CATTANI, Antônio David; HOLZMANN, Lorena. Dicionário Crítico Trabalho e Tecnologia. Porto Alegre, Zouk, 2011.

SILVA, Bárbara Suellen Santos. Nas linhas do telemarketing: uma "chamada" à precarização e flexibilização da força de trabalho em Maceió. Dissertação de mestrado, Sociologia, Universidade Federal de Alagoas. UFAL - Maceió, 2017.

SOUZA, Jessé. Os batalhadores brasileiros: nova classe média ou nova classe trabalhadora? 2. ed. Belo Horizonte, Editora UFMG, 2012. 
STEIN, Guilherme; ZYLBERSTAJN, Eduardo; ZYLBERSTAJN, Hélio. Diferencial de salários da mão de obra terceirizada no Brasil. Estudos Econômicos. São Paulo, v. 47, n. 3, 2017, pp. 587-612.

VILELA, Lailah; ASSUNÇÃO, Ada. Os mecanismos de controle da atividade do setor de teleatendimento e as queixas de cansaço e esgotamento dos trabalhadores. Caderno de Saúde Pública, Rio de Janeiro, v. 20, n. 4, 2004, pp. 1069-1078.

VENCO, Selma Borghi. Telemarketing nos bancos: o emprego que desemprega. Campinas, UNICAMP, 2003.

Centrais de teleatendimento: o surgimento dos colarinhos furta-cores? In: ANTUNES, Ricardo; BRAGA, Ruy (org.). Infoproletarios: degradação real do trabalho virtual. São Paulo, Boitempo, 2009.

Recebido em: 08/11/2017

Aprovado em: 04/07/2019

\section{Como citar este artigo:}

LEITE, Márcia de Paula e BORDIGNON, Liliane. O trabalho de teleatendimento no Brasil: um estado da arte. Contemporânea - Revista de Sociologia da UFSCar, v. 9, n. 2, maio - agosto. 2019, pp. 653-680. 